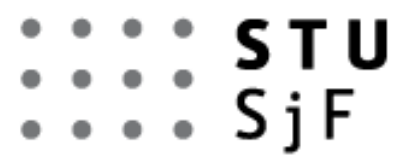

DE GRUYTER OPEN
Journal of MECHANICAL ENGINEERING

- Strojnícky časopis

VOLUME 66, NO 2, 2016

pp. $89-94$

DOI:10.1515/scjme-2016-0022

\title{
A NEW CABLE-PULLEY ALGORITHM IN RFEM
}

\author{
ŠTEKBAUER Hynek ${ }^{1}$, NĚMEC Ivan ${ }^{2}$ \\ ${ }^{1}$ FEM consulting, s.r.o., Veveři 331/95, 60200 Brno, Czech Republic, e-mail: stekbauer@fem.cz \\ ${ }^{2}$ Brno University of Technology, Faculty of Civil Engineering, Institute of Structural Mechanics, \\ Veveři 331/95, Brno, 602 00, Czech Republic, e-mail: nemec.i@fce.vutbr.cz.
}

\begin{abstract}
The cable-pulley system is widely used for its advantages. In this paper, application of a new algorithm for the calculation of cables on pulleys is presented. Unlike other algorithms, this algorithm enables to take the magnitude of the radius of each pulley into account. This new algorithm is implemented in the RFEM program because of its higher accuracy and efficiency. Comparison of the commonly used algorithm, which ignores pulley radius, and the new algorithm is presented.
\end{abstract}

KEYWORDS: Pulley, FEM, RFEM.

\section{INTRODUCTION}

Pulleys enable to create efficient cable-pulley systems which are widely used for their mechanical advantage. That is why pulleys are a part of many building and machine structures, they can be seen e.g. at crane structures, cableways and even in car engines. The set of pulleys is often a complex system, too complicated for hand calculation, and therefore there is an effort to enable calculation of such structures with the aid of computer programs. For pulleys which are a part of load bearing structures and dynamic effects are taken into account, manual calculation is completely impossible.

\section{CURRENT ALGORITHMS FOR CALCULATION OF THE CABLE-PULLEY SYSTEM}

In general, two approaches for solving cables on pulleys are used. The first approach is a connection of pulleys using 1D elements only in the centre of each pulley (Fig.1a) or at the intersection of real cable sections (Fig.1b) and defining behaviour of such a system to find an equivalent solution $[1,2,3]$. Such a solution lacks any consideration of the radii of pulleys, which inevitably leads to inaccurate results. In the first case (Fig.1a), spatial geometry of cables in the model is changed and in the second case (Fig.1b), reaction occurs in the node located out of the structure. This approach is used in programs such as LS-DYNA or RFEM. 


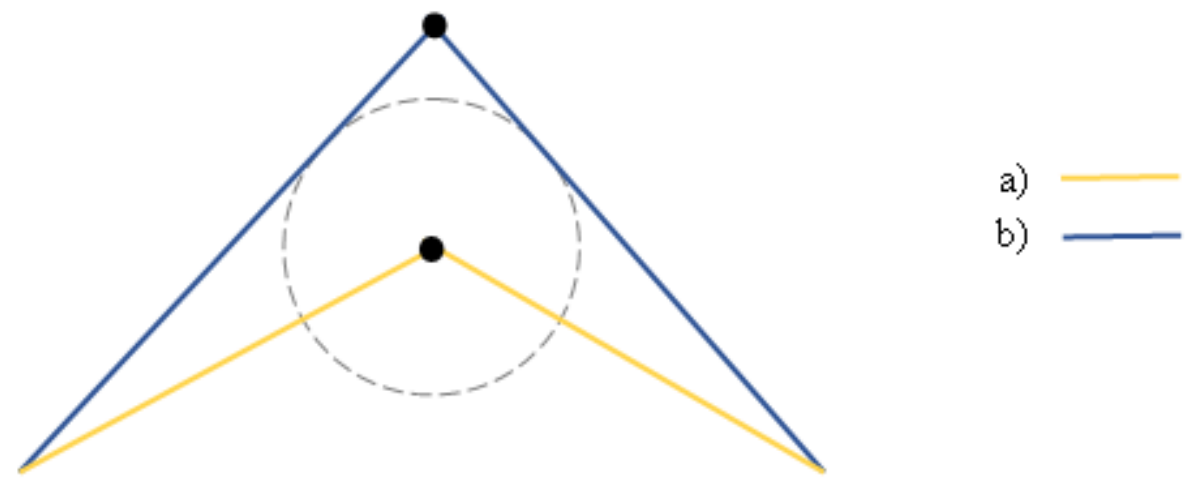

Fig. 1 - Connection of two cables in a node for the first approach

The second approach is modelling of each pulley and cable using 3D elements and adding other contact elements between these elements for the correct behaviour of the multibody system. This solution is indeed accurate for the correct model, but it is extremely laborious to create a mathematical model and calculation is also extremely time-consuming. Because of the difficulty mentioned above, use of this approach is impossible for large structures. Such approach can be used with programs like ANSYS, Nastran and Abaqus.

The current algorithm, used in the RFEM program, utilizes the first approach and for some input parameters too many iterations are required, which leads to long computing times.

\section{THE NEW ALGORITHM IN RFEM}

For reasons mentioned in the previous chapter, the new algorithm was developed using more accurate geometry (Fig.2).

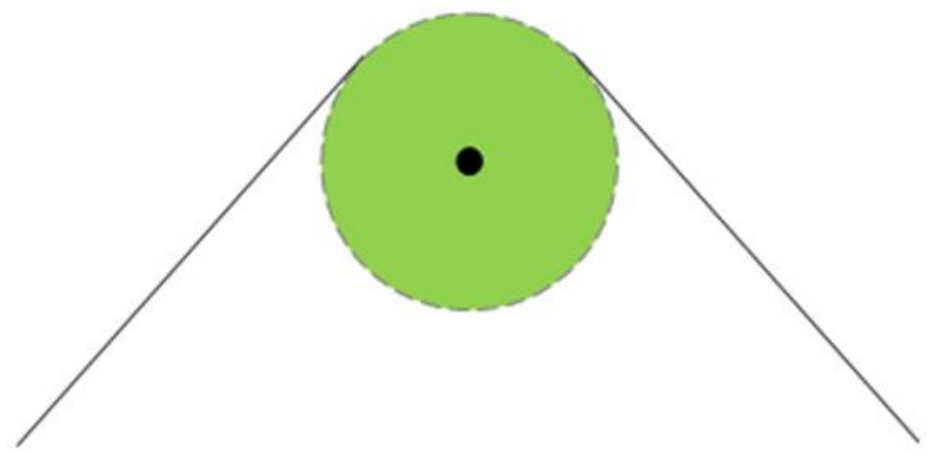

Fig. 2 - New algorithm geometry

The algorithm combines advantages of both general approaches, which leads to fast and easy pre-processing pleasant for the user, combined with more accurate results due to radii consideration [4]. Calculation speed was improved as well.

Radii consideration is accomplished by two 1D rigid elements with length equal to pulley radius. These $1 \mathrm{D}$ rigid elements are always perpendicular to the connected cable elements and rotation around the centre of the pulley is enabled in corresponding direction (Fig. 3). The new algorithm enables to add friction between bearings and the shaft [5]. 


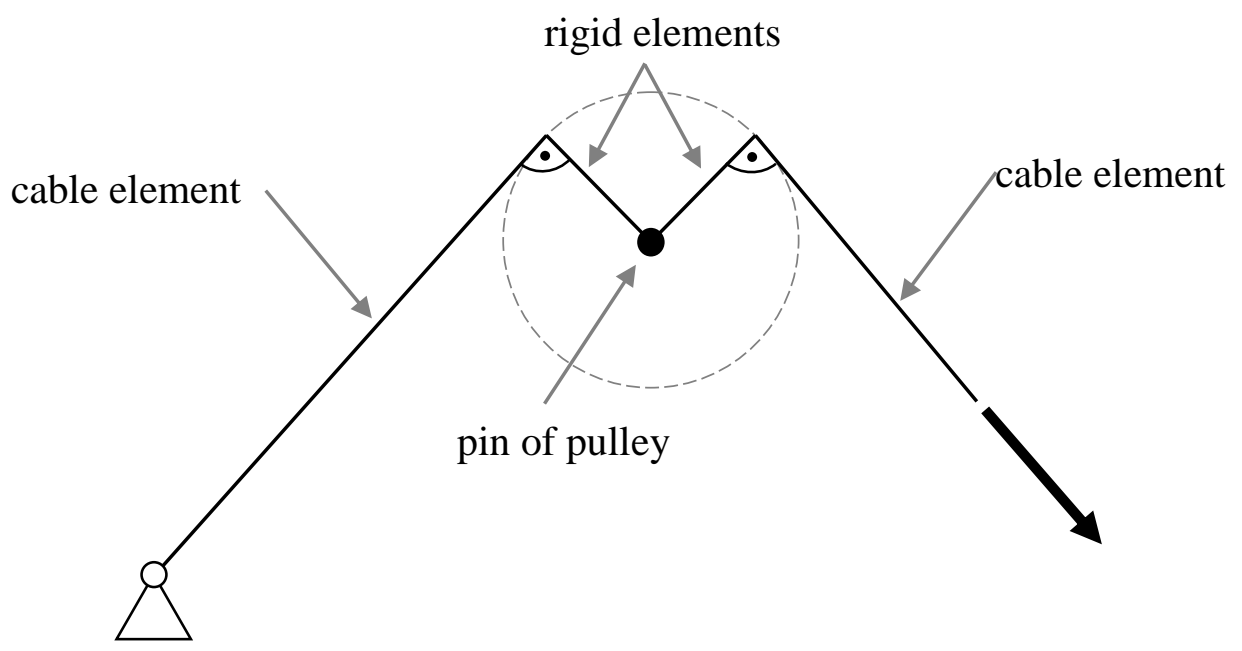

Fig. 3 - New algorithm model

\section{COMPARISON OF THE CALCULATION SPEED BETWEEN THE PREVIOUS AND THE NEW ALGORITHM IN RFEM}

The example demonstrates calculation speed of the new algorithm on a model of a cantilevered beam under a load transmitted by cables (Fig. 4). The only difference in models is consideration of pulley radius $(0.01 \mathrm{~m})$ in the new algorithm.

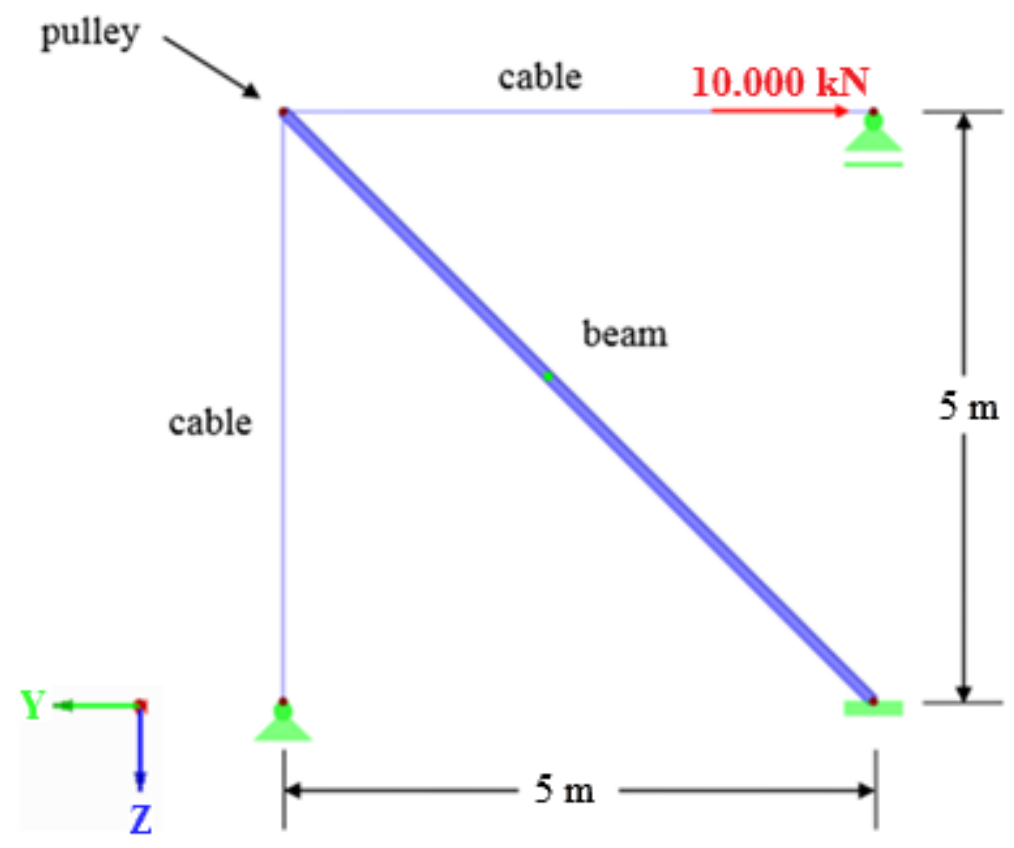

Fig. 4 - Model

The cantilevered beam is RO-section $114.3 \times 4$ and the cables are section PE 30 . All components are from steel S 235 considering isotropic linear elastic material model with $\mathrm{E}=210 \mathrm{GPa}$ and $\mathrm{G}=81 \mathrm{GPa}$. 1D elements with 12 degrees of freedom (3 displacements and 3 rotations in each node) are used for the beam and 1D elements with only 6 degrees of freedom (3 displacements in each node) for the cables. The calculation model is described and calculated in the plane YZ. 


\begin{tabular}{|l|c|c|c|c|}
\hline & \multicolumn{4}{|c|}{ Cross-Section properties } \\
\hline Cross-Section name & $\begin{array}{c}\text { Moment of } \\
\text { inertia J } \\
{\left[\mathrm{cm}^{4}\right]}\end{array}$ & $\begin{array}{c}\text { Moments } \\
\text { of inertia } \\
\text { Iy, Iz }\left[\mathrm{cm}^{4}\right]\end{array}$ & $\begin{array}{c}\text { Axial area } \\
\mathrm{A} \\
{\left[\mathrm{cm}^{2}\right]}\end{array}$ & $\begin{array}{c}\text { Shear areas } \\
\mathrm{Ay}, \mathrm{Az} \\
{\left[\mathrm{cm}^{2}\right]}\end{array}$ \\
\hline RO 114.3x4 & 422.13 & 211.07 & 13.86 & 6.88 \\
\hline PE 30 & 1.73 & 0.87 & 2.46 & 2.07 \\
\hline
\end{tabular}

Tab. 1 - Results control of both algorithms

Iteration diagrams on Fig. 5-6 shows speed-up of the new algorithm against the old one.

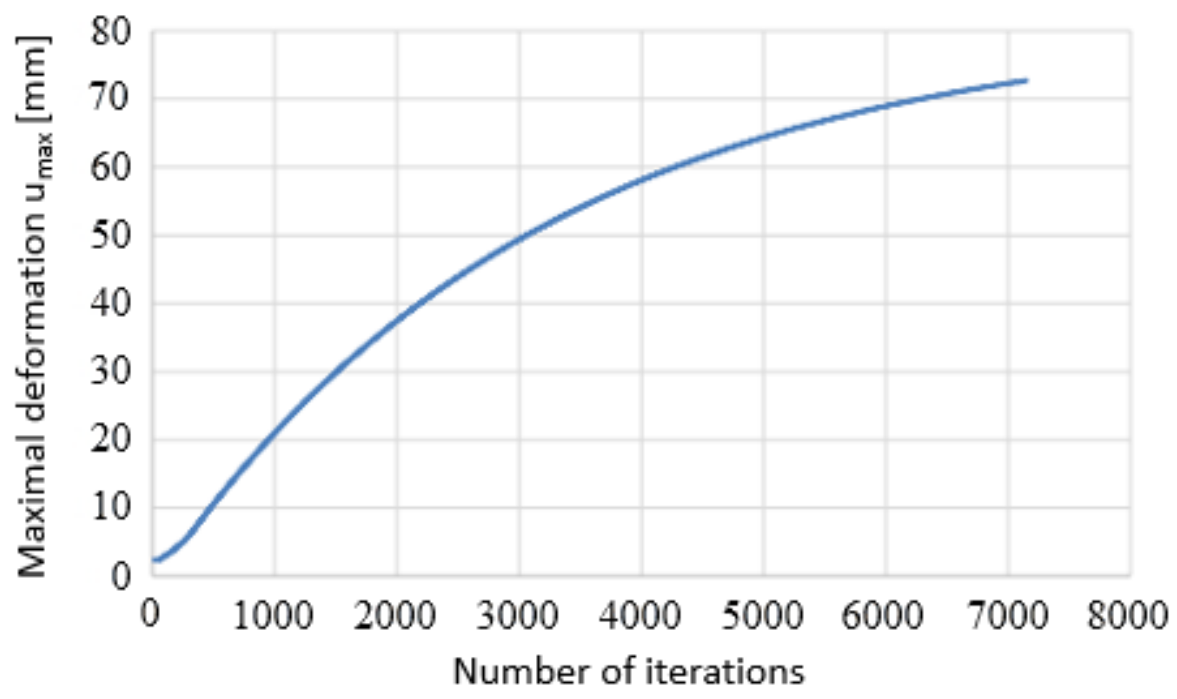

Fig. 5 - Iteration diagram of the old algorithm, time of calculation: $217.26 \mathrm{~s}$

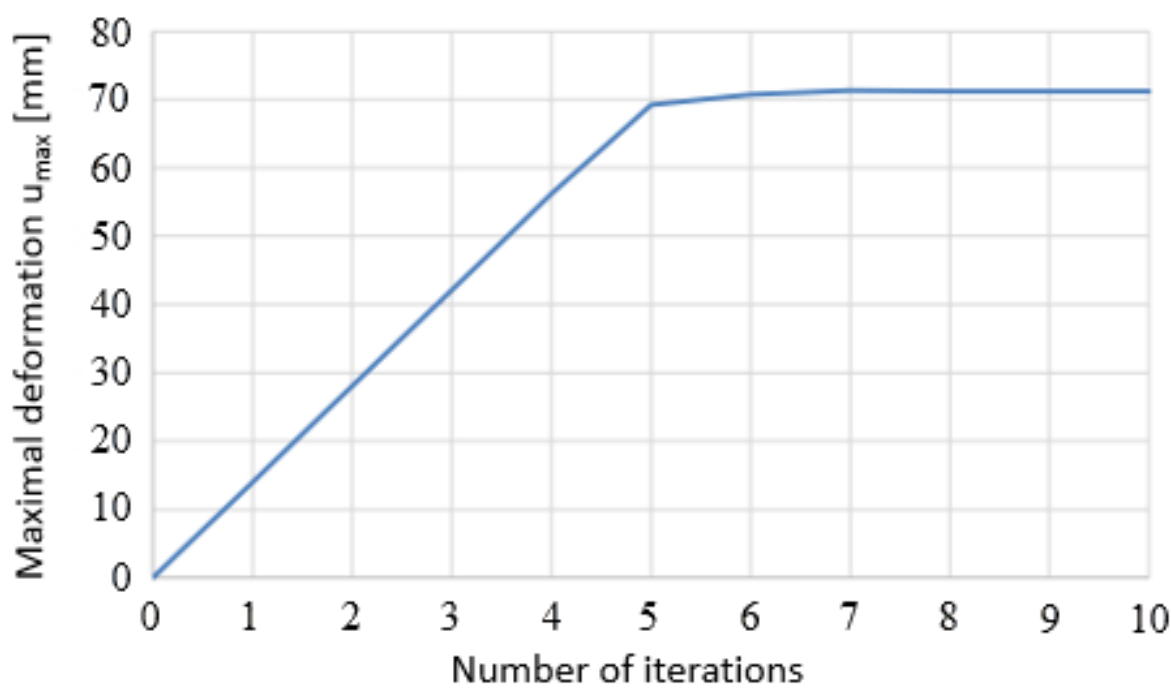

Fig. 6 - Iteration diagram of the new algorithm, time of calculation: $0.19 \mathrm{~s}$ 


\begin{tabular}{|c|c|c|c|c|}
\hline Calculation status & $\begin{array}{c}\text { Old } \\
\text { algorithm } \\
{[\mathrm{kN}]}\end{array}$ & $\begin{array}{c}\text { Old } \\
\text { algorithm } \\
\text { deviation }\end{array}$ & $\begin{array}{c}\text { New } \\
\text { algorithm } \\
{[\mathrm{kN}]}\end{array}$ & $\begin{array}{c}\text { New } \\
\text { algorithm } \\
\text { deviation }\end{array}$ \\
\hline Sum of load in direction $\mathrm{Y}$ & 10 & \multirow[t]{2}{*}{$0.00 \%$} & 10 & \multirow[t]{2}{*}{$0.00 \%$} \\
\hline Sum of support forces in direction $Y$ & 10 & & 10 & \\
\hline Sum of load in direction $\mathrm{Z}$ & 0.96 & \multirow[t]{2}{*}{$2.14 \%$} & 0.96 & \multirow[t]{2}{*}{$0.00 \%$} \\
\hline Sum of support forces in direction $\mathrm{Z}$ & 0.94 & & 0.96 & \\
\hline
\end{tabular}

Tab. 2 - Results control of both algorithms

Solution of the example gives similar results for both algorithms. Result control (Tab. 2) for the old algorithm shows deviation $2.14 \%$ in direction $\mathrm{Z}$ while the new algorithm converged with zero deviation. Besides the small deviation, the main advantage of the new algorithm is its speed. The old algorithm needs 7148 iterations (Fig. 5) while the new algorithm needs only 10 iterations (Fig. 6). The number of iterations directly involves the time of calculation. In this example, the new algorithm is approximately 1100 times faster with the time of calculation being $0.19 \mathrm{~s}$, compared to time of the old algorithm $-217.26 \mathrm{~s}$.

\section{CONCLUSION}

The new algorithm for solving cables on pulleys was developed. The pulley wheel is modelled by rigid elements perpendicular to the cable elements and connected by a hinge to the pin of the pulley. The main drawback is limitation of rotation in each iteration to 4 degrees due to the linearization in each iteration. Friction between bearings and the shaft is neglected, infinity friction is assumed between the cable and the pulley surface. The presented solution is more efficient and accurate than the existing algorithm used in RFEM software. The comparison of results and the calculation speed was presented. The example showed that the new algorithm for solving cables on pulleys is more powerful and more accurate than the previous solution.

\section{ACKNOWLEDGEMENT}

This research was partially supported by the project FAST-J-15-2803.

\section{REFERENCES}

[1] Aufaure, M. A finite element of cable passing through a pulley. Computers \& Structures, 1993, Vol. 46, no.5, pp. 807-812.

[2] Ju, F., Choo, Y. Dynamic Analysis of Tower Cranes. Journal of Engineering Mechanics, 2005, Vol. 131, no.1, pp. 88-96.

[3] Ju, F., Choo, Y. Super element approach to cable passing through multiple pulleys. Mechanics International Journal of Solids and Structures, 2005, Vol. 42, no.11-12, pp. 3533-3547.

[4] Taylor, R., Mikulas Jr., M., Hedgepeth, J. A linearized discrete radius pulley model for finite element analysis, 35th Structures, Structural Dynamics, and Materials Conference, Hilton Head, SC, U.S.A., 1994, Vol. 6, pp. 2599-2606.

[5] Handa, A., Chawla, V. Experimental evaluation of mechanical properties of friction welded dissimilar steels under varying axial pressures, Strojnícky časopis - Journal of Mechanical Engineering, Vol. 66, no. 1, 2016, pp. 27-36, ISSN 0039-2472. 
